\title{
Early findings in a pilot study of anterior cervical interbody fusion in which recombinant human bone morphogenetic protein-2 was used with poly(L-lactide-co-D,L-lactide) bioabsorbable implants
}

\author{
Todd H. Lanman, M.D., and Thomas J. Hopkins, Ph.D., M.D. \\ California Spine Group, Century City Hospital, Los Angeles, California
}

\begin{abstract}
Object. The goal of this study was to assess the efficacy of bioabsorbable interbody spacers in cervical spine fusion. Methods. The authors report on a prospective examination of 20 patients with degenerative cervical disc disease who underwent anterior cervical fusion at 28 total levels. The authors used Infuse bone graft (that is, recombinant human bone morphogenetic protein-2 applied to an absorbable collagen sponge and contained within a Cornerstone-HSR bioabsorbable spacer. Multiple-level fusions were performed in $30 \%$ of these patients. At 3 months postfusion, radiographs and computerized tomography scans demonstrated bridging bone in $100 \%$ of the patients. Improvement from baseline scores in physical functioning, mental health, and bodily pain was demonstrated at 3 months postoperatively according to results of the Short Form-36 Version 2 health survey. There were no device-related complications.

Conclusions. The results in this series indicate that the use of Cornerstone-HSR as a bioabsorbable interbody spacer in combination with Infuse bone graft may be an alternative treatment for cervical spine fusion.
\end{abstract}

\section{KEY WORDS • anterior cervical fusion - bone morphogenetic protein • bioabsorbable implant • interbody cage}

Anterior cervical discectomy and interbody fusion with autograft has been a common treatment for management of degenerative or traumatic instability of the cervical spine. This procedure has reportedly yielded fusion success rates from as low as $56 \%$ to as high as $100 \% .{ }^{17}$ The variability in reported results can be ascribed to multiple factors, including surgical technique, criteria used to define fusion, length of follow up, and number of levels fused. The success rates are lower when multiple levels are fused than for single-level fusions. Although various methods have been developed to decrease rates of nonunion after cervical fusion, grafting of autologous bone from the iliac crest remains the most common procedure. Nevertheless, use of autologous bone grafts from the iliac crest may be associated with postoperative complications such as hematoma, infection, numbness, donor site pain, lateral femoral cutaneous nerve injury, pelvic fracture, and muscle herniation. ${ }^{12}$ To avoid the morbidity associated with donor site complications, allograft may be used as an alternative source of bone; however, the use of allograft may result in slower recovery times. Delayed union or nonunion of the allograft can result in the need

Abbreviations used in this paper: $\mathrm{ACDF}=$ anterior cervical discectomy and interbody fusion; CT = computerized tomography; $\mathrm{PLa}=\operatorname{poly}(\mathrm{L}-$ lactide-co-D,L-lactide $) ;$ rhBMP-2 = recombinant human bone morphogenetic protein-2; SF-36 = Short Form-36. for revision surgery. The use of anterior plate fixation to provide immediate stability, and of intervertebral cages or spacers and rhBMP-2 has been introduced to minimize failure rates in cervical fusion.

Intervertebral cages were designed to prevent collapse and pseudarthrosis that was sometimes seen with fusions in which only bone graft was used. ${ }^{5,7}$ To be effective, intervertebral cages must be stable enough to be used as a stand-alone device. These cages were traditionally composed of autograft, cadaveric allograft, titanium, or stainless steel. The inability to assess fusion radiographically when metal cages are used has prompted the development of spacers composed of other materials. The optimal spacer would be rigid at implantation, become less so over time, and would degrade completely when the healing cycle has been completed. ${ }^{6,20}$

Biomaterials such as carbon fiber, hydroxyapatite, and calcium phosphate ceramics were studied in animals and were found to be subject to fatigue fractures, collapse, and extrusion..$^{20}$ Bioabsorbable materials have emerged as an alternative that could provide the attributes of immediate stability, relative radiolucency, gradual transfer of stress to the fusion site, and breakdown products that have no mutagenic or immunogenic properties. Bioabsorbable polymers have properties consistent with these criteria. Once the fusion has matured, the materials slowly resorb by bulk hydrolysis into carbon dioxide and water. 
HYDROSORB devices, which are intended for support of weak bone tissue (distributed by Medtronic Sofamor Danek, Memphis, TN), have been used by some investigators as potential interbody devices. The HYDROSORB copolymer of polylactide, 70:30 PLa, has been used in various laboratory, preclinical, and clinical studies in a variety of clinically relevant situations. Laboratory tests have yielded evidence that the 70:30 PLa degrades over a period of 18 to 36 months. ${ }^{1}$

Animal studies have been conducted to assess resorbable devices used for interbody fusion. The authors of one study investigated devices constructed of a 70:30 PLa polymer in 25 sheep over a period of 24 months; the animals were treated with and without added rhBMP-2. ${ }^{15}$ Comparable steadily increasing degrees of fusion were observed over the time period in mechanical and histological studies conducted on spines treated with the resorbable spacer filled with either rhBMP-2 or autograft bone. Additionally, as the implant resorbed at the 24-month period, the space was replaced with remodeled bone, there was normal bone mineralization adjacent to the device, and no osteolysis was found. These findings are comparable to those in another study, in which lumbar interbody devices composed of poly-L-lactide were investigated in 36 goats. ${ }^{18}$ The fusion was complete at approximately 2 years, and was faster and more complete than with identically shaped titanium cages. Tissue reaction in both studies was described as mild to moderate.

Limited clinical experience has been reported for the use of bioabsorbable interbody spacers in spinal fusion in humans. ${ }^{1,2}$ In these posterior lumbar interbody fusion procedures, local "morcellized" autologous bone was packed within and around the devices. At 1 year postfusion, results show clinical outcomes equivalent to those reported historically with allograft bone spacers. Preliminary re- sults (1-9 months) in 60 patients who underwent transforaminal lumbar interbody fusion procedures in which two HYDROSORB bioabsorbable implants were used per level are encouraging. ${ }^{11}$ The majority of patients experienced symptomatic relief, and there were no implant failures.

The use of rhBMP-2 has been shown to initiate osteoinduction and to achieve spinal arthrodesis in animals $^{8,9,13-15,19}$ and in humans. Clinical studies of lumbar ${ }^{4,10}$ and cervical fusion ${ }^{3}$ in humans have demonstrated consistent and clear osteoinduction when rhBMP-2 is impregnated onto an absorbable collagen sponge (Infuse) and placed in an intervertebral spacer. Here we present 3- to 6month follow-up information on a series of 20 patients in whom a bioabsorbable interbody spacer was combined with Infuse interbody filler for anterior cervical fusions at one to three levels.

\section{CLINICAL MATERIAL AND METHODS}

We conducted a prospective evaluation of medical charts, radiographs, and CT scans in all patients who had undergone $\mathrm{ACDF}$ in which a bioabsorbable orthopedic implant, Cornerstone-HSR, was used as an interbody spacer to contain Infuse bone graft (both supplied by Medtronic Sofamor Danek). Cornerstone-HSR is a noncrystalline polylactide copolymer with a 70:30 ratio of poly(Llactide) to poly(D,L-lactide).

A total of 20 patients were chosen to undergo this surgical procedure between March 31, 2003, and July 3, 2003. Patients ranged in age from 22 to 62 years (mean $46.2 \pm 8.77$ years). There were six women (30\%) and 14 men $(70 \%)$. All patients had one-, two-, or three-level cervical disc disease. Specific patient data are shown in Table 1.

TABLE 1

Summary of characteristics in 20 patients who underwent ACDF*

\begin{tabular}{|c|c|c|c|c|c|c|}
\hline \multirow{2}{*}{$\begin{array}{l}\text { Case } \\
\text { No. }\end{array}$} & \multirow{2}{*}{$\begin{array}{l}\text { Age (yrs), } \\
\text { Sex }\end{array}$} & \multirow[b]{2}{*}{ Diagnosis } & \multirow[b]{2}{*}{ Specific Levels } & \multirow{2}{*}{$\begin{array}{l}\text { Length of } \\
\text { Stay (days) }\end{array}$} & \multicolumn{2}{|c|}{ Outcome } \\
\hline & & & & & 3 Mos & $6 \mathrm{Mos}$ \\
\hline 1 & $56, \mathrm{M}$ & disc herniation & C5-6, C6-7 & 1 & fusion & fusion \\
\hline 2 & $52, \mathrm{M}$ & DDD & $\mathrm{C} 4-5$ & 0 & fusion & fusion \\
\hline 3 & $51, \mathrm{~F}$ & discogenic pain & C4-5, C5-6, C6-7 & 1 & fusion & fusion \\
\hline 4 & $53, \mathrm{M}$ & disc herniation & $\mathrm{C} 3-4, \mathrm{C} 4-5$ & 0 & fusion & fusion \\
\hline 5 & $41, \mathrm{M}$ & DDD & C6-7 & 0 & fusion & fusion \\
\hline 6 & $49, \mathrm{~F}$ & nonunion & $\mathrm{C} 4-5, \mathrm{C} 6-7$ & 32 & fusion & fusion \\
\hline 7 & $22, \mathrm{M}$ & disc herniation & C6-7 & 0 & fusion & fusion \\
\hline 8 & $37, \mathrm{~F}$ & disc herniation & C6-7 & 0 & fusion & fusion \\
\hline 9 & $53, \mathrm{M}$ & nonunion & $\mathrm{C} 4-5$ & 0 & fusion & fusion \\
\hline 10 & $39, \mathrm{M}$ & disc herniation & C5-6 & 0 & fusion & fusion \\
\hline 11 & $38, \mathrm{M}$ & disc herniation & C6-7 & 0 & fusion & fusion \\
\hline 12 & $45, \mathrm{~F}$ & disc herniation & C5-6 & 0 & fusion & fusion \\
\hline 13 & $50, \mathrm{M}$ & DDD & C6-7 & 0 & fusion & fusion \\
\hline 14 & $46, \mathrm{~F}$ & spondylosis, DDD, nonunion & C6-7 & 0 & fusion & fusion \\
\hline 15 & $62, \mathrm{~F}$ & spondylosis & $\mathrm{C} 4-5, \mathrm{C} 5-6, \mathrm{C} 6-7$ & 2 & fusion & fusion \\
\hline 16 & $48, \mathrm{M}$ & nonunion & $\mathrm{C} 7-\mathrm{T} 1$ & 3 & fusion & fusion \\
\hline 17 & $43, \mathrm{M}$ & disc herniation & C6-7 & 0 & fusion & fusion \\
\hline 18 & $39, \mathrm{M}$ & spondylosis & C5-6 & 1 & fusion & NA \\
\hline 19 & $54, \mathrm{M}$ & discogenic pain & C5-6 & 0 & fusion & NA \\
\hline 20 & $46, \mathrm{M}$ & DDD & C5-6, C6-7 & 1 & fusion & NA \\
\hline
\end{tabular}

* $\mathrm{DDD}=$ degenerative disc disease; $\mathrm{NA}=$ not available. 
Each patient underwent a standard anterior cervical discectomy. The rhBMP-2 solution was reconstituted and applied to a piece of collagen sponge according to the directions for use of Infuse. The epidural space was sealed with a 2-mm layer of Tisseel thrombin glue, which acted as a barrier between the Infuse and spinal canal. The Infuse was then contained within the Cornerstone-HSR absorbable interbody implants, which were tapped into place for each level to be fused. Anterior cervical plating systems were used in conjunction with the interbody spacer and graft. The Atlantis Anterior Cervical Plate System (Medtronic Sofamor Danek) was used in $75 \%$ of cases and the Blackstone Anterior Cervical Plate System (Blackstone Medical, Springfield, MA) was used in $25 \%$.

As part of a standardized evaluation process, preoperative plain radiographs and CT scans were obtained in all patients to document degenerative disc disease, and patients were asked to complete a baseline SF-36 survey questionnaire. Plain radiographs, CT scans, and SF-36 surveys were obtained at follow-up visits to determine the fusion rates and functional outcomes after surgery. Fusion was determined according to results observed on radiographs and CT scans. Fusion was defined as bridging bone in the interbody space from the vertebra through the graft to the adjacent vertebra.

The postoperative regimen included the following instructions to be followed for 6 weeks until the first followup visit: 1) no lifting more than 15 to 20 pounds; 2) walk daily; 3 ) may drive 3 days after surgery; and 4) may shower and get the wound wet. None of the patients wore a neck brace or collar after surgery.

\section{RESULTS}

The majority of participants $(65 \%)$ were treated as outpatients, whereas $30 \%$ spent 1 to 3 days in the hospital postoperatively. One patient (Case 6) had an extended hospital stay of 32 days due to complications; this was the third ACDF for this patient. She suffered severe dysphagia postoperatively and required a feeding tube until she was able to swallow at 1 month postsurgery. She did well after that and exhibited solid bridging bone at her 3-month follow-up visit.

One-level fusion was performed in 14 patients $(70 \%)$, two-level in four (20\%), and three-level in two (10\%), for a total of 28 levels. At the 3-month follow-up point, successful interbody fusion was observed on CT scans in 20 patients $(100 \%)$, including the two in whom three levels were fused. At the 6-month follow-up visit, 17 patients underwent CT scanning, and all 17 continued to show interbody fusion. The patient in Case 1 was a 56-year-old man with disc herniation at C5-6 and C6-7. Figure 1 consists of his preoperative magnetic resonance image and the sagittal view from his 6-week CT scan, whereas Fig. 2 displays sagittal and axial views from his 3- and 6-month CT scans.

There were few postsurgical complications. One patient (Case 6) experienced severe dysphagia, as described earlier. Another patient (Case 16) had undergone a previous ACDF at C5-6, C6-7, and C7-T1 in which allograft was used. In this series he underwent surgery for a nonunion at C7-T1, but required additional surgery 3 months postop-
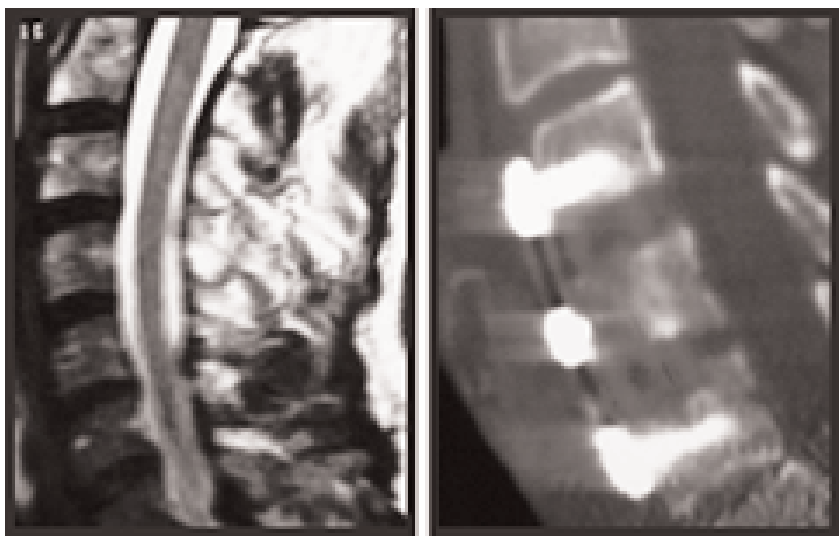

Fig. 1. Case 1. Left: Preoperative magnetic resonance image, sagittal view. Right: Sagittal CT scan obtained at 6 weeks.

eratively for a nonunion at C5-6. After the second surgery, solid fusion extended down through all levels. There were no device-related complications.

Patients' general health status was assessed using the
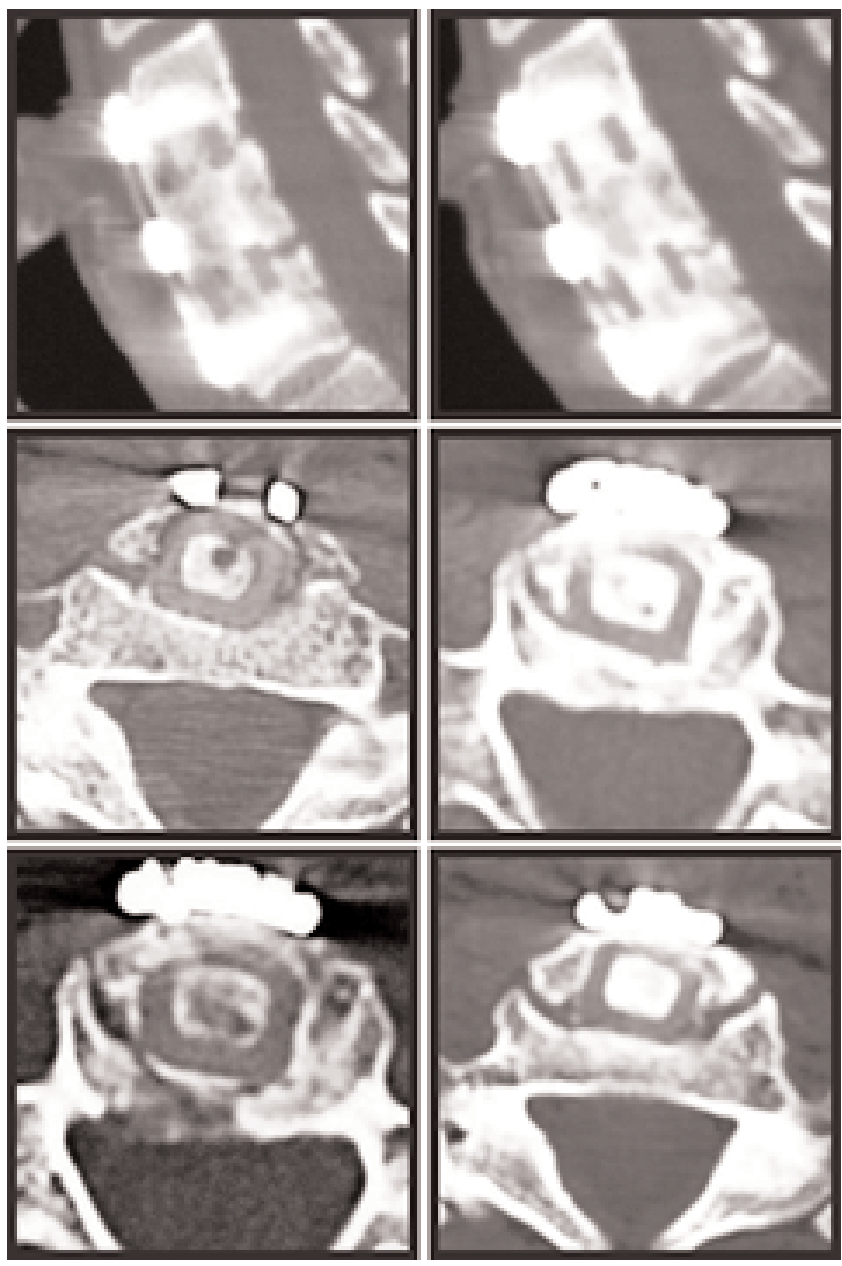

Fig. 2. Case 1. Follow-up CT scans obtained at 3 months on the left and 6 months on the right. Upper: Sagittal views. Center: Axial views of C5-6. Lower: Axial views of C6-7. 
T. H. Lanman and T. J. Hopkins

SF-36 Version 2 health survey (Table 2). Improvement from baseline (increase in score) at 3 months postoperatively was noted in all scores except those for general health. Physical functioning scores improved by 5.7 points, whereas bodily pain scores increased only slightly (2.2 points). Five patients have completed SF-36 surveys at 6 months postoperatively; Table 3 shows that physical functioning continued to improve in four of them. Bodily pain scores improved in three patients, and remained the same as the baseline in one. One patient (Case 16) reported increased bodily pain at the 6-month time point that may be attributed to a second surgery performed 3 months postoperatively.

\section{DISCUSSION}

Bioabsorbable materials have been used for various applications in spinal surgery, including iliac reconstruction, cervical plating and screws, and lumbar interbody spacers. The early and intermediate strength of bioabsorbable materials allow a progressive transfer of stresses to the fusion site. In an animal study in which titanium interbody cages were compared with those made of bioabsorbable poly-L-lactic acid, van Dijk, et al., ${ }^{16}$ concluded that the reduced stiffness of the bioabsorbable cages enhanced lumbar interbody fusion and that their radiolucent properties were useful in determining the rate of interbody fusion within the cages. In another animal study in which polylactide cages packed with either autologous bone or rhBMP-2 were evaluated, the investigators found the bioabsorbable interbody spacers to be a viable alternative to metal, with the advantages of increased radiolucency and decreased stiffness. ${ }^{15}$

This analysis is one of the first reported patient series in which early results of the use of rhBMP-2 in conjunction with a bioabsorbable interbody spacer for ACDF are shown. In this patient series it was possible to assess fusion as early as 3 months postoperatively because of the radiolucency of the spacer. The fusion rates at 3 months are similar to those reported at 6 months in a study in which rhBMP-2 was used with an allograft interbody spacer and cervical plating. ${ }^{3}$ This experience with Infuse and Cornerstone-HSR appears to document faster and improved fusion rates than those in our experience using

TABLE 2

The mean scores for SF-36 health status

\begin{tabular}{lccc}
\hline \hline & \multicolumn{3}{c}{ Mean Score } \\
\cline { 2 - 4 } \multicolumn{1}{c}{ SF-36 Scale } & Preop & 3 Mos & $\begin{array}{c}\text { Difference } \\
\text { (3 mos - preop) }\end{array}$ \\
\hline $\begin{array}{l}\text { physical functioning } \\
\text { role limitations due to } \\
\quad \text { physical health problems }\end{array}$ & 56.2 & 61.9 & 5.7 \\
$\begin{array}{l}\text { role limitations due to } \\
\quad \text { emotional health problems }\end{array}$ & 40.6 & 42.1 & 1.5 \\
$\begin{array}{l}\text { vitality } \\
\text { mental health }\end{array}$ & 57.6 & 61.9 & 4.3 \\
$\begin{array}{l}\text { social functioning } \\
\text { bodily pain } \\
\text { general health }\end{array}$ & 47.4 & 48.1 & 0.7 \\
\hline & 57.6 & 61.0 & 3.4 \\
& 35.4 & 42.9 & 7.4 \\
& 31.0 & 33.2 & 2.2 \\
& 60.0 & 58.2 & -1.8 \\
\hline
\end{tabular}

TABLE 3

Scores for SF-36 health status in patients with 6-month data*

\begin{tabular}{ccc}
\hline \hline Case No. \& Time Period & Physical Function & Bodily Pain \\
\hline $2 \quad$ & & \\
preop & 70.0 & 25.0 \\
3 mos & 40.0 & 22.5 \\
6 mos & 25.0 & 45.0 \\
6 preop & 45.0 & 0.0 \\
3 mos & 30.0 & 0.0 \\
6 mos & 70.0 & 0.0 \\
$8 \quad$ preop & 35.0 & 22.5 \\
3 mos & 35.0 & 35.0 \\
6 mos & 50.0 & 37.5 \\
$9 \quad$ & - & - \\
preop & 65.0 & 22.5 \\
3 mos & 70.0 & 37.5 \\
6 mos & & 65.0 \\
preop & 70.0 & - \\
3 mos & - & 25.0 \\
6 mos & 75.0 & \\
\hline
\end{tabular}

* — indicates that the patient did not complete a survey at this time point.

Infuse with allograft. The combination of CornerstoneHSR or allograft and Infuse is considered by the Food and Drug Administration to be an off-label use in the cervical spine.

This report involves a small number of patients in whom a relatively short follow-up time has accumulated. It is encouraging to note, however, that bridging bone was clearly visible on plain radiographs and CT scans at the 3-month follow-up examination. It is too early to draw conclusions about this combination of materials for anterior cervical fusion, but the initial results in this pilot study indicate that this procedure may provide an alternative treatment for anterior cervical fusion. These patients will continue to receive follow-up care to confirm long-term success with the use of a bioabsorbable interbody spacer in conjunction with rhBMP-2 for anterior cervical fusion.

\section{Disclosure}

Dr. Lanman is a paid consultant for Medtronic Sofamor Danek.

\section{References}

1. Alexander JT, Branch CL Jr, Subach BR, et al: Applications of a resorbable interbody spacer via a posterior lumbar interbody fusion technique. Orthopedics 25 (Suppl 10):S1185-S1189, 2002

2. Austin RC, Branch CL, Alexander JT: Novel bioresorbable interbody fusion spacer-assisted fusion for correction of spinal deformity. Neurosurg Focus 14 (1):Article 11, 2003

3. Baskin DS, Ryan P, Sonntag V, et al: A prospective, randomized, controlled cervical fusion study using recombinant human bone morphogenetic protein- 2 with the Cornerstone-SR allograft ring and the Atlantis anterior cervical plate. Spine 28: 1219-1225, 2003

4. Boden SD, Zdeblick TA, Sandhu HS, et al: The use of rhBMP2 in interbody fusion cages. Definitive evidence of osteoinduction in humans: a preliminary report. Spine 25:376-381, 2000

5. Brantigan JW, Steffee AD, Lewis ML, et al: Lumbar interbody 


\section{Pilot study of fusion with rhBMP-2 packed in PLa implants}

fusion using the Brantigan I/F cage for posterior lumbar interbody fusion and the variable pedicle screw placement system: two-year results from a Food and Drug Administration investigation device exemption clinical trial. Spine 25:1437-1446, 2000

6. Cahill DW, Martin GJ Jr, Hajjar MV, et al: Suitability of bioresorbable cages for anterior cervical fusion. J Neurosurg (Spine 2) 98:195-201, 2003

7. Hacker RJ, Cauthen JC, Gilbert TJ, et al: A prospective randomized multicenter clinical evaluation of an anterior cervical fusion cage. Spine 25:2646-2655, 2000

8. Hecht BP, Fischgrund JS, Herkowitz HN, et al: The use of recombinant human bone morphogenetic protein 2 (rhBMP-2) to promote spinal fusion in a nonhuman primate anterior interbody fusion model. Spine 24:629-636, 1999

9. Kandziora F, Bail H, Schmidmaier G, et al: Bone morphogenetic protein-2 application by a poly(D,L-lactide)-coated interbody cage: in vivo results of a new carrier for growth factors. J Neurosurg (Spine 1) 97:40-48, 2002

10. Kleeman TJ, Ahn UM, Talbot-Kleeman A: Laparoscopic anterior lumbar interbody fusion with rhBMP-2: a prospective study of clinical and radiographic outcomes. Spine 26: 2751-2756, 2001

11. Lowe TG, Coe JD: Bioresorbable polymer implants in the unilateral transforaminal lumbar interbody fusion procedure. Orthopedics 25 (Suppl 10):S1179-S1183, 2002

12. Malloy KM, Hilibrand AS: Autograft versus allograft in degenerative cervical disease. Clin Orthop 394:27-38, 2002

13. Martin GJ Jr, Boden SD, Titus L, et al: New formulations of demineralized bone matrix as a more effective graft alternative in experimental posterolateral lumbar spine arthrodesis. Spine 24: 637-645, 1999

14. Takahashi T, Tominaga $\mathrm{T}$, Watabe $\mathrm{N}$, et al: Use of porous hydroxyapatite graft containing recombinant human bone morphogenetic protein-2 for cervical fusion in a caprine model. J Neurosurg (Spine 4) 90:224-230, 1999

15. Toth JM, Wang M, Scifert JL, et al: Evaluation of 70/30 D,LPLa for use as a resorbable interbody fusion cage. Orthopedics 25 (Suppl 10):S1131-S1140, 2002

16. van Dijk M, Smit TH, Sugihara S, et al: The effect of cage stiffness on the rate of lumbar interbody fusion: an in vivo model using poly(1-lactic acid) and titanium cages. Spine 27:682-688, 2002

17. Wigfield CC, Nelson RJ: Nonautologous interbody fusion materials in cervical spine surgery: how strong is the evidence to justify their use? Spine 26:687-694, 2001

18. Wuisman PJ, van Dijk M, Smit TH: Resorbable cages for spinal fusion: an experimental goat model. Orthopedics 25 (Suppl 10):S1141-S1148, 2002

19. Zdeblick TA, Ghanayem AJ, Rapoff AJ, et al: Cervical interbody fusion cages. An animal model with and without bone morphogenetic protein. Spine 23:758-766, 1998

20. Zdeblick TA, Phillips FM: Interbody cage devices. Spine 28: S2-S7, 2003

Manuscript received January 15, 2004.

Accepted in final form February 27, 2004.

Address reprint requests to: Todd H. Lanman, M.D., Southern California Association of Neurological Surgeons, 8631 West Third Street, Suite 945E, Los Angeles, California 90048. 